\title{
Receipt of cardiac screening does not influence 1-year post-cerebrovascular event mortality
}

Jason J. Sico, MD, Fitsum Baye, MS, Laura J. Myers, PhD, John Concato, MD, Jared Ferguson, BS, Eric M. Cheng, MD, Farid Jadbabaie, MD, Zhangsheng Yu, PhD, Gregory Arling, PhD, Alan J. Zillich, PharmD, Mathew J. Reeves, PhD, Linda S. Williams, MD, and Dawn M. Bravata, MD

Correspondence

Dr. Sico

jason.sico@yale.edu

Neurology: Clinical Practice June 2018 vol. 8 no. 3 192-200 doi:10.1212/CPJ.0000000000000465

\section{Abstract}

\section{Background}

American Heart Association/American Stroke Association expert consensus guidelines recommend consideration of cardiac stress testing to screen for occult coronary heart disease (CHD) among patients with ischemic stroke/TIA who have a high-risk Framingham Cardiac Risk Score (FCRS). Whether this guideline is being implemented in routine clinical practice, and the association of its implementation with mortality, is less clear.

\section{Methods}

Study participants were Veterans with stroke/TIA $(\mathrm{n}=11,306)$

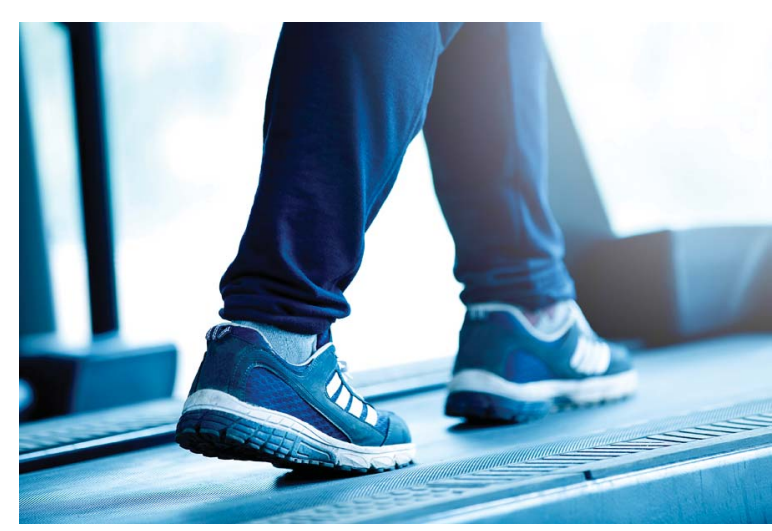
during fiscal year 2011 who presented to a VA Emergency Department or who were admitted. Patients were excluded $(n=6,915)$ based on prior CHD/angina/chest pain history, receipt of cardiac stress testing within 18 months prior to cerebrovascular event, death within 90 days of discharge, discharge to hospice, transfer to a non-VA acute care facility, or missing/unknown race. FCRS $\geq 20 \%$ was classified as high risk for CHD. ICD-9 and Common Procedural Terminology codes were used to identify receipt of any cardiac stress testing.

\section{Results}

Among 4,391 eligible patients, $62.8 \%(n=2,759)$ had FCRS $\geq 20 \%$. Cardiac stress testing was performed infrequently and in similar proportion among high-risk $(4.5 \%[123 / 2,759])$ vs low/intermediate-risk $(4.4 \%[72 / 1,632])$ patients (adjusted odds ratio [aOR] 0.77, 95\% confidence interval $[\mathrm{CI}] 0.54-1.10)$. Receipt of stress testing was not associated with reduced 1 -year mortality (aOR 0.59, CI 0.26-1.30).

\section{Conclusions}

In this observational cohort study of patients with cerebrovascular disease, cardiac screening was relatively uncommon and was not associated with 1-year mortality. Additional work is needed to understand the utility of $\mathrm{CHD}$ screening among high-risk patients with cerebrovascular disease.

Neurology Service (JJS), Clinical Epidemiology Research Center (CERC) (JJS, JC), and Medical Service (JC, FJ), VA Connecticut Healthcare System, West Haven; Department of Neurology (JJS), Center for Neuroepidemiological and Clinical Research (JJS), and Department of Internal Medicine (JJS, JC, JF, FJ), Yale School of Medicine, New Haven, CT; VA Health Services Research and Development (HSR\&D) Center for Health Information and Communication (CHIC) (FB, LJM, JF, LSW, DMB) and the HSR\&D Stroke Quality Enhancement Research Initiative (QUERI) (FB, LJM, JF, LSW, DMB), Richard L. Roudebush VA Medical Center, Indianapolis; Departments of Biostatistics (FB, ZY), Internal Medicine (LJM, DMB), and Neurology (LSW, DMB), Indiana University School of Medicine, Indianapolis; Department of Neurology (EMC), VA Greater Los Angeles Healthcare System and David Geffen School of Medicine, University of California, Los Angeles; College of Health and Human Services (GA), Purdue University School of Nursing; Department of Pharmacy Practice (AJZ), Purdue University College of Pharmacy, West Lafayette, IN; Department of Epidemiology and Biostatistics (MJR), Michigan State University, East Lansing; and Regenstrief Institute (LSW, DMB), Indianapolis, IN.

Funding information and disclosures are provided at the end of the article. Full disclosure form information provided by the authors is available with the full text of this article at Neurology.org/cp.

The Article Processing Charge was funded by Department of Veterans Affairs (VA), Health Services Research and Development.

This is an open access article distributed under the terms of the Creative Commons Attribution-NonCommercial-NoDerivatives License 4.0 (CC BY-NC-ND), which permits downloading and sharing the work provided it is properly cited. The work cannot be changed in any way or used commercially without permission from the journal. 
Ischemic stroke and coronary heart disease (CHD) share many vascular risk factors (e.g., hypertension), ${ }^{1,2}$ with $20 \%-30 \%$ of stroke patients having symptomatic CHD and another $40 \%$ having silent cardiac ischemia. ${ }^{3}$ Although cardiac evaluation among patients with acute or subacute stroke largely focuses on discerning whether an event was caused by a cardioembolic source, ${ }^{4}$ the American Heart Association/American Stroke Association (AHA/ASA) also recommends consideration of cardiac screening for asymptomatic $\mathrm{CHD}$ based on a high-risk Framingham Cardiac Risk Score (FCRS $\geq 20 \%$ ).

Investigating the presence of occult $\mathrm{CHD}$ among patients with cerebrovascular disease may be clinically prudent, given that $\mathrm{CHD}$ is a leading cause of morbidity and mortality in this population., ${ }^{3,5}$ Determining whether patients with cerebrovascular disease also have coronary atherosclerotic disease may have important treatment implications, ${ }^{1,10,11}$ but a previous study attempting to implement this guideline found that outpatient providers did not pursue testing, given the lack of evidence regarding whether such screening improved poststroke outcomes. 6

In the absence of a prospective study to ascertain whether implementation of cardiac screening among patients with a recent cerebrovascular event improves outcomes, we used administrative data to determine whether (1) patients with cerebrovascular disease routinely received cardiac stress testing based on a high-risk FCRS and (2) screening for asymptomatic CHD was associated with reduced 1-year allcause mortality. We also conducted chart reviews to identify reasons why clinicians pursued cardiac stress testing.

\section{Methods}

\section{Overview}

This study was a secondary analysis of Veterans Health Administration (VA) administrative data, which were used to identify Veterans $(n=11,306)$ with a primary diagnosis of acute ischemic stroke or TIA who presented to a VA emergency department or were admitted to a VA medical center in fiscal year (FY) 2011 (i.e., October 2010-September 2011). We excluded patients (n $=6,097$ ) based on medical history of $\mathrm{CHD}$, myocardial infarction (MI), angina/chest pain, or receipt of percutaneous transluminal coronary angioplasty/percutaneous coronary intervention within the previous 5 years (as identified by a combination of ICD-9 and Common Procedural Terminology [CPT] codes); cardiac stress test within the 18 months prior to their stroke/TIA event ${ }^{12,13}$; death within the 90 days of discharge or discharge to hospice; transfer to a non-VA acute care facility; or missing/unknown race. These exclusions were not mutually exclusive. The final analytic sample included 4,391 Veterans.

\section{Standard protocol approvals, registrations, and patient consents}

Institutional review board approval was obtained for this research.
Cardiac stress testing for patients with cerebrovascular disease based on

\section{a high-risk FCRS is not performed as part of routine clinical care.}

\section{Data}

Data for demographic factors, medical comorbidities (e.g., $\mathrm{CHD}$ and $\mathrm{MI}$ ), symptoms (e.g., angina/chest pain), and discharge medications were obtained from existing VA data sources: VHA Austin and fee-basis (which captures data related to Veterans receiving care outside of VHA medical centers) inpatient and outpatient data files in the 5 years pre cerebrovascular event (FY 2005-2012); a combination of ICD and $\mathrm{CPT}$ codes were used to identify medical history variables. Race/ethnicity data were collected from the Centers for Medicare and Medicaid Services (CMS) vital status file and if missing or unavailable, supplemented with data from the VA's Functional Status Outcomes Database and VHA Austin inpatient and outpatient data files, if available. Only $1 \%$ of race values were unknown and these patients were excluded from the analyses because calculation of the FCRS requires race.

FCRS was calculated for each patient based on race- and sexspecific pooled cohort equations that accounted for age, sex, race, total and high-density lipoprotein (HDL) cholesterol, systolic blood pressure (SBP; including treated or untreated), diabetes, and current smoking status. The results are used to estimate an individual's 10-year risk of cardiovascular event, and can be reliably and accurately calculated from administrative data. ${ }^{14,15}$ SBP, total cholesterol, and HDL cholesterol values were based on values at discharge from the index stroke or TIA event when available; if no discharge measurement was available, the most recent value prior to discharge was used (table e-1, links.lww. com/CPJ/A25). Pharmacy Benefits Management data were used to identify medications (e.g., antihypertensive medications), Corporate Data Warehouse data for blood pressure, and laboratory data for total and HDL cholesterol.

Data for covariates related to indications other than a high FCRS (e.g., troponin I $>0.1 \mathrm{mcg} / \mathrm{L}$ ) were collected 180 days prior to the cerebrovascular event and within 90 days after the index. Angina/chest pain prior to the index event was an exclusion to initial cohort construction; therefore, this covariate reflects angina/chest pain that occurred within 90 days of the index cerebrovascular event.

The primary outcome of interest was receipt of any cardiac stress testing, either pharmacologic (e.g., gated Persantine study) or nonpharmacologic (e.g., treadmill stress test) among high-risk patients within 90 days of hospital discharge. ICD-9 and CPT codes were used to identify cardiac stress testing 
Table 1 Patient characteristics at baseline, stratified by receipt of cardiac stress test ${ }^{\mathrm{a}}(n=4,391)$

\begin{tabular}{|c|c|c|c|c|}
\hline Characteristic & Stress test performed $(n=195)$ & Stress test not performed $(n=4,196)$ & $p$ Value & Total $(n=4,391)$ \\
\hline Age, $y$, mean \pm SD & $66.1 \pm 10.1$ & $66.9 \pm 11.6$ & 0.25 & $66.9 \pm 11.6$ \\
\hline Sex: Male & 97.9 & 95.5 & 0.11 & 95.7 \\
\hline Race: White/nonblack & 85.1 & 72.8 & 0.0001 & 73.3 \\
\hline FCRS $\geq 20 \%$ & 63.1 & 62.8 & 0.94 & 63.1 \\
\hline \multicolumn{5}{|l|}{ Index event } \\
\hline Stroke & 68.2 & 69.9 & 0.61 & 69.8 \\
\hline TIA & 31.8 & 30.1 & 0.61 & 30.2 \\
\hline \multicolumn{5}{|l|}{ Comorbidities } \\
\hline Hypertension & 82.1 & 77.1 & 0.11 & 77.4 \\
\hline Diabetes & 43.1 & 36.5 & 0.06 & 36.8 \\
\hline Hyperlipidemia & 76.4 & 57.9 & $<0.0001$ & 58.7 \\
\hline Current smoker & 40.5 & 35.7 & 0.17 & 35.9 \\
\hline Atrial fibrillation & 14.9 & 9.7 & 0.02 & 9.9 \\
\hline Congestive heart failure & 15.9 & 7.0 & $<0.0001$ & 7.4 \\
\hline Carotid artery disease & 35.4 & 16.0 & $<0.0001$ & 16.9 \\
\hline Carotid endarterectomy & 13.8 & 3.4 & $<0.0001$ & 3.9 \\
\hline Peripheral vascular disease & 11.8 & 11.0 & 0.72 & 11.0 \\
\hline Dementia & 2.6 & 5.2 & 0.10 & 5.1 \\
\hline Chronic obstructive pulmonary disease & 21.5 & 18.0 & 0.21 & 18.2 \\
\hline Pneumonia & 6.2 & 4.8 & 0.38 & 4.8 \\
\hline Cancer $^{\mathbf{b}}$ & 10.3 & 11.3 & 0.66 & 11.2 \\
\hline Chronic kidney disease & 12.8 & 12.1 & 0.75 & 10.5 \\
\hline Charlson Comorbidity Index, mean (SD) & $1.1(1.6)$ & $1.3(1.8)$ & 0.21 & $1.3(1.8)$ \\
\hline \multicolumn{5}{|l|}{ Indications for cardiac stress testing } \\
\hline Troponin I $<0.1 \mu \mathrm{g} / \mathrm{L}$ & 8.7 & 4.8 & 0.02 & 5.0 \\
\hline Angina/chest pain & 34.9 & 5.2 & $<0.0001$ & 6.5 \\
\hline Lightheadedness & 9.7 & 4.8 & 0.002 & 5.1 \\
\hline Shortness of breath & 12.8 & 4.4 & $<0.001$ & 4.8 \\
\hline Abnormal ECG & 8.7 & 2.5 & $<0.001$ & 2.8 \\
\hline Arrhythmia $^{c}$ & 19.5 & 9.8 & $<0.0001$ & 10.2 \\
\hline Aortic stenosis/regurgitation & 3.6 & 3.0 & 0.65 & 3.0 \\
\hline Mitral stenosis/regurgitation & 1.0 & 1.9 & 0.38 & 1.8 \\
\hline \multicolumn{5}{|l|}{ Medications } \\
\hline Statin use & 76.4 & 71.3 & 0.12 & 71.6 \\
\hline \multicolumn{5}{|l|}{ Antihypertensive use } \\
\hline All BP medications & 86.2 & 76.8 & 0.002 & 77.2 \\
\hline Beta-blocker & 43.6 & 32.8 & 0.002 & 33.3 \\
\hline Diuretics & 34.9 & 35.8 & 0.79 & 35.8 \\
\hline
\end{tabular}


Table 1 Patient characteristics at baseline, stratified by receipt of cardiac stress test ${ }^{\mathrm{a}}(\mathrm{n}=4,391)$ (continued)

\begin{tabular}{|c|c|c|c|c|}
\hline Characteristic & Stress test performed $(n=195)$ & Stress test not performed $(n=4,196)$ & $p$ Value & Total $(n=4,391)$ \\
\hline ACEI/ARB & 65.6 & 51.5 & 0.0001 & 52.1 \\
\hline Antiplatelet use & 89.2 & 83.2 & 0.027 & 83.5 \\
\hline No. of pre-event NEXUS visits, mean (SD) ${ }^{d}$ & $4.1(3.4)$ & $3.8(3.9)$ & 0.051 & $3.8(3.9)$ \\
\hline
\end{tabular}

Abbreviations: ACEI/ARB = angiotensin-converting enzyme inhibitor/angiotensin II receptor blocker; BP = blood pressure; FCRS = Framingham Cardiac Risk Score.

a Percent shown unless otherwise indicated.

${ }^{\mathrm{b}}$ Cancer includes: solid tumor (with and without metastatic disease), leukemia, lymphoma, and multiple myeloma.

c Arrhythmia (not including atrial fibrillation).

${ }^{\mathrm{d}}$ NEXUS visits include primary care and selected specialty care visits.

(table e-2, links.lww.com/CPJ/A25). Receipt of cardiac stress testing was identified using VA administrative data, linked VA CMS data, and VA fee-basis files; the combination of these data sources allowed for identification of testing provided for patients performed within and outside of the VA.

The secondary outcome of interest was all-cause 1-year poststroke mortality, as measured from the VA's Vital Status File (VSF). The VA VSF contains dates of death from all VA beneficiaries. Death information in the VA VSF originates from a variety of VA and non-VA sources (e.g., CMS). Research has shown that the VA VSF is relatively complete and accurate when compared with information contained in the National Death Index (NDI), with more than $98.3 \%$ of deaths in the VA VSF confirmed with deaths in the NDI. ${ }^{16}$ Given that our study population was assembled based on FY11 data, with mortality data being extracted at the end of FY13, enough time had elapsed to capture mortality events occurring 1 year after the index cerebrovascular event.

Data were also collected through retrospective chart review on a sample of electronic medical records to determine whether providers ordered stress testing based on a patient's high risk FCRS, and to collect other indications for (e.g., symptoms of chest pain or angina, preoperative evaluation for carotid endarterectomy [CEA]) and results of stress testing (e.g., positive dobutamine stress test in the area of left anterior descending artery). Chart reviews were performed by abstractors who were specially trained for the study.

\section{Statistical analyses}

We describe demographic and clinical characteristics of participants based on receipt of cardiac stress testing and for the overall study sample, using $\chi^{2}$ or Fisher exact tests for categorical variables and Wilcoxon rank-sum or $t$ tests for continuous variables. We then compared these characteristics among patients with FCRS $\geq 20 \%$, also based on receipt of stress testing. Two separate multivariable logistic regression models were used to examine (1) whether cardiac stress testing was performed more frequently for patients with FCRS $\geq 20 \%$ compared with patients with FCRS $<20 \%$ and (2) the association of receipt of cardiac stress testing and 1-year all-cause mortality among the entire cohort. A generalized linear mixed model with logit link was used to model both outcomes. A random intercept of VA facility was used to adjust for the correlation among patients within the same facility. Covariates associated with outcomes in the bivariate random effect model with $p$ value $<0.25$, or clinically important variables (e.g., FCRS), were included in the multivariable models, and nonsignificant covariates were dropped from the multivariable models one at a time. A ratio of 10 outcome events per variable was maintained during model construction. ${ }^{17,18}$ For each regression model, discrimination ( $C$ statistics) was calculated to gauge model performance. Because missing data were rare, no imputations were made. Given that the low 1-year mortality among patients with FCRS $\geq 20 \%$ who received cardiac stress testing precluded a meaningful analysis of a population for which the AHA/ASA expert consensus guidelines recommend was intended, we also calculated the sample size required to have $80 \%$ statistical power, with a 2 -sided $\alpha$ of 0.05 , to detect a $20 \%$ difference in mortality among patients with a FCRS $\geq 20 \%$ who did and did not receive cardiac stress testing. All statistical analyses used SAS version 9.2 (SAS Institute, Cary, NC).

\section{Data availability}

Anonymized data not published within this article will be made available by request from any qualified investigator if approved by our Research Ethics Board. All analyses must be conducted behind the VA firewall. Investigators interested in working with the data should contact the authors.

\section{Results}

The mean age of the 4,391 patients in the study was 66.9 years $( \pm$ SD 11.6$)$ and $73.3 \%$ were not black; 3,067 had an ischemic stroke $(69.8 \%)$ and 1,324 had a TIA $(30.2 \%)$ as their index event (table 1). A high FCRS was calculated for $62.8 \%$ $(2,759 / 4,391)$ of patients.

Stress testing within 90 days of discharge occurred in $4.4 \%$ of all patients $(195 / 4,391)$; the rate of stress testing was nearly identical among those with high and low/intermediate risk FCRS: $4.5 \%(123 / 2,759)$ for high and $4.4 \%(72 / 1,632)$ for 
Table 2 Baseline characteristics among patients with high Framingham cardiac risk score $(n=2,759)^{a}$

\begin{tabular}{|c|c|c|c|}
\hline Variable & Stress test performed, $\%$ & Stress test not performed, $\%$ & $p$ Value \\
\hline Age, y, mean (SD) & 70.1 (8.9) & $72.0(10.5)$ & 0.03 \\
\hline Race: White/nonblack & 83.7 & 73.1 & 0.009 \\
\hline Sex: Male & 99.2 & 97.7 & 0.27 \\
\hline \multicolumn{4}{|l|}{ Index event } \\
\hline Stroke & 72.4 & 71.3 & 0.80 \\
\hline TIA & 27.6 & 28.7 & 0.80 \\
\hline \multicolumn{4}{|l|}{ Comorbidities } \\
\hline Hypertension & 88.6 & 83.7 & 0.15 \\
\hline Diabetes & 61.0 & 50.0 & 0.02 \\
\hline Hyperlipidemia & 81.3 & 61.6 & $<0.0001$ \\
\hline Current smoker & 42.3 & 36.4 & 0.19 \\
\hline Atrial fibrillation & 16.3 & 12.6 & 0.23 \\
\hline Congestive heart failure & 17.1 & 8.5 & 0.001 \\
\hline Carotid artery disease & 35.0 & 17.4 & $<0.0001$ \\
\hline Carotid endarterectomy & 14.6 & 3.5 & $<0.0001$ \\
\hline Peripheral vascular disease & 12.2 & 12.6 & 0.91 \\
\hline Dementia & 4.1 & 7.2 & 0.18 \\
\hline Chronic obstructive pulmonary disease & 22.8 & 18.9 & 0.28 \\
\hline Pneumonia & 4.9 & 5.3 & 0.93 \\
\hline Cancer $^{\mathbf{b}}$ & 9.8 & 13.4 & 0.24 \\
\hline Chronic kidney disease & 17.1 & 16.0 & 0.75 \\
\hline Charlson Comorbidity Index, mean (SD) & $1.2(1.6)$ & $1.5(1.9)$ & 0.09 \\
\hline \multicolumn{4}{|l|}{ Indications for cardiac stress testing } \\
\hline Troponin I $<0.1 \mu g / L$ & 8.9 & 5.3 & 0.09 \\
\hline Angina/chest pain & 34.1 & 4.7 & $<0.0001$ \\
\hline Lightheadedness & 8.9 & 4.9 & 0.05 \\
\hline Shortness of breath & 13.8 & 5.0 & $<0.0001$ \\
\hline Abnormal ECG & 11.4 & 2.7 & $<0.0001$ \\
\hline Arrhythmia $^{c}$ & 18.7 & 10.7 & 0.006 \\
\hline Aortic stenosis/regurgitation & 4.9 & 3.8 & 0.54 \\
\hline Mitral stenosis/regurgitation & 0.8 & 2.2 & 0.31 \\
\hline \multicolumn{4}{|l|}{ Medications } \\
\hline Statin use & 82.9 & 74.3 & 0.03 \\
\hline \multicolumn{4}{|l|}{ Antihypertensive use } \\
\hline All BP medications & 89.4 & 85.1 & 0.19 \\
\hline Beta-blocker & 48.0 & 37.6 & 0.02 \\
\hline Diuretics & 39.0 & 40.1 & 0.81 \\
\hline
\end{tabular}


Table 2 Baseline characteristics among patients with high Framingham cardiac risk score $(\mathrm{n}=2,759)^{\mathrm{a}}(\mathrm{continued})$

\begin{tabular}{|c|c|c|c|}
\hline Variable & Stress test performed, \% & Stress test not performed, $\%$ & $p$ Value \\
\hline ACEI/ARB & 74.0 & 57.6 & 0.0003 \\
\hline Antiplatelet use & 88.6 & 85.9 & 0.39 \\
\hline No. of pre-event NEXUS visits ${ }^{d}$ & $4.2(3.3)$ & $4.0(4.0)$ & 0.19 \\
\hline
\end{tabular}

Abbreviations: ACEI/ARB = angiotensin-converting enzyme inhibitor/angiotensin II receptor blocker; BP = blood pressure; FCRS = Framingham Cardiac Risk Score.

a Percent shown unless otherwise indicated.

${ }^{b}$ Cancer includes solid tumor (with and without metastatic disease), leukemia, lymphoma, and multiple myeloma.

c Arrhythmia (not including atrial fibrillation).

d NEXUS visits include primary care and selected specialty care visits.

low/intermediate FCRS. Patients receiving stress testing (compared with patients not receiving stress testing) were more likely to be not black with a history of hyperlipidemia, atrial fibrillation, congestive heart failure ( $\mathrm{CHF})$, carotid artery disease, CEA, elevated troponin I during admission, angina, lightheadedness, shortness of breath, abnormal ECG, and arrhythmia (other than atrial fibrillation), and to be prescribed antihypertensive and antiplatelet medications at discharge (table 1). Similar reasons for obtaining screening occurred in a sample restricted to high-risk patients (table 2). After adjusting for FCRS and sociodemographic and baseline characteristics, patients had a higher odds of receiving a cardiac stress test if they were not black, male, with a history of hyperlipidemia, diabetes, CHF, carotid artery disease, CEA, angina, lightheadedness, shortness of breath, abnormal ECG, or arrhythmia (other than atrial fibrillation). FCRS was not associated with receipt of stress testing in unadjusted or adjusted analyses (adjusted odds ratio [aOR] 0.77; confidence interval [CI] 0.54-1.10; table 3).

Among the 4.4\% (195/4,391) of patients receiving cardiac stress testing within 90 days of discharge, 3.6\% (7/195) were dead at 1 year; $5.6 \%(234 / 4,196)$ of patients who did not receive stress testing were dead at 1 year. Neither unadjusted nor adjusted (aOR 0.59; 95\% CI 0.26-1.30) analyses demonstrated an association between cardiac stress testing and mortality. Among the $62.8 \%(2,759 / 4,391)$ of patients with a high FCRS, $6.8 \%(188 / 2,759)$ were dead at 1 year; $3.3 \%$ $(53 / 1,632)$ with a low/intermediate risk FCRS were dead at 1 year. High FCRS was associated with higher 1-year mortality (aOR 1.48; 95\% CI 1.06-2.07; $p<0.001$; table 4).

In a subsample $(\mathrm{n}=3,099)$ of patients who did not have reasons to receive cardiac stress testing other than high FCRS (e.g., abnormal ECG), stress testing was not performed more commonly among patients with high FCRS compared to low/ intermediate FCRS $(2.5 \%$ vs $2.4 \% ; p=0.833)$. In contrast, patients who had other reasons for receiving cardiac stress testing more commonly had stress testing performed compared to those who did not have other reasons to receive stress testing (9.13\% vs $2.48 \%$; $p<0.0001)$.
To detect a mortality difference among patients with FCRS $\geq 20 \%$ who did and did not receive cardiac stress testing, we estimated (for $50 \%$ screening prevalence) that 2,178 patients would be required in each group. In contrast, this analysis included 195 patients who received stress testing and 4,196 who did not receive testing.

In charts available for review $(\mathrm{n}=17)$, chest pain/angina and preoperative/perioperative assessment for CEA/stent procedure or "other surgery" accounted for $53 \%(n=9 / 17)$ of the cardiac screening indications; none of these procedures or surgeries was performed based on high-risk FCRS (table e-3, links.lww.com/CPJ/A25).

Table 3 Association between Framingham cardiac risk score and receipt of cardiac stress testing adjusted for patient characteristics at baseline $(n=4,391)$

\begin{tabular}{llll}
\hline Effect & aOR & $95 \% \mathrm{Cl}$ & $p$ Value \\
\hline FCRS $\geq \mathbf{2 0} \%$ vs FCRS $<\mathbf{2 0} \%$ & 0.77 & $0.54-1.10$ & 0.15 \\
\hline Race (white/nonblack) & 1.70 & $1.09-2.65$ & 0.02 \\
\hline Male vs female & 3.39 & $1.07-10.75$ & 0.04 \\
\hline Hyperlipidemia & 1.79 & $1.25-2.58$ & 0.002 \\
\hline Diabetes & 1.73 & $1.20-2.49$ & 0.004 \\
\hline Congestive heart failure & 2.62 & $1.65-4.15$ & $<0.0001$ \\
\hline Carotid artery disease & 1.77 & $1.19-2.65$ & 0.006 \\
\hline Carotid endarterectomy & 2.84 & $1.60-5.03$ & 0.006 \\
\hline Lightheadedness & 1.87 & $1.07-3.27$ & 0.03 \\
\hline Angina/chest pain & 9.49 & $6.60-13.63$ & $<0.0001$ \\
\hline Shortness of breath & 1.95 & $1.16-3.26$ & 0.02 \\
\hline Abnormal EGC & 2.24 & $1.18-4.28$ & 0.02 \\
\hline Arrhythmia ${ }^{\text {Charlson Comorbidity Index }}$ & 0.87 & $0.78-0.96$ & 0.009 \\
\hline
\end{tabular}

Abbreviations: $\mathrm{aOR}=$ adjusted odds ratio; $\mathrm{Cl}=$ confidence interval; FCRS = Framingham Cardiac Risk Score.

${ }^{a}$ Arrhythmia (not including atrial fibrillation). 
Possible explanations for our

observed racial difference in cardiac

stress testing among patients with

a cerebrovascular event include race-

based differences in access to care, perceptions of testing and procedures, and socioeconomic

status.

\section{Discussion}

Cardiac stress testing for patients with cerebrovascular disease based on a high-risk FCRS is not performed as part of routine clinical care. Given our limited ability to model 1-year all-cause mortality among patients for whom the AHA/ASA expert consensus guideline recommends consideration of screening (i.e., FCRS $\geq 20 \%$ ), we cannot comment on whether routine screening for high-risk patients with cerebrovascular disease should be performed from a mortality perspective. When examining the association among all patients with cerebrovascular disease irrespective of their FCRS, we found no mortality benefit for cardiac screening. We also identified important predictors of receiving cardiac stress testing.

Although the FCRS was originally intended to prognosticate 10-year risk of CHD-related events, it has been used to predict shorter-term outcomes among patients with cerebrovascular disease. $^{5,7}$ A high-risk FCRS has been shown to predict a higher hazard of MI (adjusted hazard ratio 3.70; 95\% CI 2.14-6.38) and MI or vascular death (adjusted hazard ratio 2.21; 95\% CI 1.48-3.28) among noncardioembolic poststroke patients. ${ }^{7}$ Our finding that high-risk FCRS was associated with higher 1-year mortality among our cohort of stroke and TIA patients is similar to another study demonstrating the association between increasing FCRS and likelihood of death and disability during an index admission with stroke. ${ }^{5}$

An important consideration regarding the implementation of CHD screening based on high-risk FCRS is the prevalence of $\mathrm{CHD}$ among asymptomatic patients. Prior studies have examined the prevalence of asymptomatic $\mathrm{CHD}$ in patients with cerebrovascular disease, with an estimated 20\%-40\% having silent cardiac ischemia as diagnosed by cardiac stress testing. ${ }^{19}$ When considering the prevalence of angiographically diagnosed CHD, $62 \%$ of patients with cerebrovascular disease and without CHD had coronary artery plaques, whereas $26 \%$ of patients had coronary artery stenosis $\geq 50 \%$. These patients had markedly increased risk of vascular events despite receiving best medical management for asymptomatic $\mathrm{CHD}{ }^{20}$ Noting the potential importance of $\mathrm{CHD}$ and $\mathrm{CHD}$-related events among patients with cerebrovascular disease, AHA/ ASA Scientific Statement expert consensus guidelines recommended that providers should consider evaluating for occult CHD for patients with FCRS $\geq 20 \%$. $^{3}$

A study examining the implementation of this recommendation for poststroke CHD screening found that a minority of eligible patients received testing. ${ }^{6}$ When testing was performed, $14 \%$ of patients had a positive stress test, with these patients going on to be prescribed $\beta$-blockers. ${ }^{6}$ While we found that clinicians utilized cardiac stress testing for several approved indications (e.g., chest pain/angina), ${ }^{21,22}$ our results also demonstrate relative underuse of stress testing among asymptomatic patients with cerebrovascular disease and high-risk FCRS.

In recent years, ischemic stroke, and more specifically atherosclerotic stroke, has appropriately been recognized as an important cardiac risk equivalent, given the association between stroke and the approximate $\geq 20 \%$ absolute risk of fatal

Table 4 Unadjusted and adjusted associations between cardiac screening 1-year mortality

\begin{tabular}{|c|c|c|c|c|}
\hline Effect & Unadjusted OR $(95 \% \mathrm{CI})^{\mathrm{a}}$ & Model 1: adjusted OR $(95 \% \mathrm{CI})^{\mathrm{b}}$ & Model 2: adjusted OR $(95 \% \mathrm{Cl})^{\mathrm{c}}$ & Model 3: adjusted OR $(95 \% \mathrm{CI})^{\mathrm{d}}$ \\
\hline $\begin{array}{l}\text { Receipt of cardiac } \\
\text { screening }\end{array}$ & $0.62(0.28-1.35)$ & $0.62(0.28-1.34)$ & $0.61(0.28-1.32)$ & $0.59(0.26-1.30)$ \\
\hline $\begin{array}{l}\text { Not receiving } \\
\text { cardiac screening }\end{array}$ & Reference & Reference & Reference & Reference \\
\hline FCRS $\geq 20 \%$ & - & $2.18(1.59-2.98)$ & $2.18(1.59-3.00)$ & $1.48(1.06-2.07)$ \\
\hline FCRS $<20 \%$ & Reference & Reference & Reference & Reference \\
\hline
\end{tabular}

Abbreviations: $\mathrm{Cl}=$ confidence interval; FCRS = Framingham Cardiac Risk Score; OR = odds ratio.

a $p$ Value: 0.22 , C statistic: 0.70 .

b Model 1: Adjusted for FCRS; an interaction between receipt of cardiac screening and FCRS was nonsignificant. $C$ statistic: 0.70 .

c Model 2: Adjusted for FCRS, sex, and race. C statistic: 0.68 .

d Model 3: Adjusted for FCRS, atrial fibrillation, congestive heart failure, being a current smoker, chronic kidney disease, dementia, pneumonia, cancer,

Charlson Comorbidity Index, troponin I > $0.1 \mu \mathrm{g} / \mathrm{L}$, and statin use. C statistic: 0.77 . 
or nonfatal MI or sudden death. ${ }^{23}$ Another rationale for considering ischemic stroke as a cardiac equivalent has been to promote the delivery of effective preventive strategies among all cardiac risk equivalents. ${ }^{23}$ This becomes especially important when considering that patients with cerebrovascular disease generally have poorer control of their vascular risk factors than patients with other cardiac equivalents. ${ }^{14,24,25}$

A key finding of these analyses was the identification of predictors of receiving cardiac stress testing. Not surprisingly, patients with well-established reasons to receive cardiac stress testing (e.g., angina/chest pain), conditions associated with increased vascular risk (e.g., hyperlipidemia), and carotid artery disease, as another cardiac equivalent, had a greater odds of receiving stress testing (tables 1 and 3$).^{23}$ Although diabetes was associated with a higher odds of receiving cardiac screening in this cohort, a study conducted among patients with diabetes suggests that cardiac screening should not be pursued when the intent is to decrease cardiac event rates. ${ }^{24}$ Outside of the cerebrovascular literature, a lower burden of medical comorbidities was associated with an increased likelihood of receiving stress testing. ${ }^{26}$ One explanation for this finding is that patients with a greater degree of comorbidity may be "too sick" or have medical contraindications to undergo cardiac stress testing. We were surprised to detect racial differences related to receiving cardiac screening. Data from nonstroke populations indicate that black patients with cardiac disease are less likely to receive revascularization procedures both within ${ }^{27}$ and outside of the VA. ${ }^{28}$ Among Medicare beneficiaries, nonblack men are more likely to receive cardiac screening then black men. ${ }^{29}$ Possible explanations for our observed racial difference in cardiac stress testing among patients with a cerebrovascular event include race-based differences in access to care, perceptions of testing and procedures, and socioeconomic status. As the VA is not a fee-for-service enterprise, the ability of patients to pay for procedures is less likely to contribute to the observed racial disparity.

The strengths of our study include the large sample size and the ability to control for several important sociodemographic and baseline medical and neurologic conditions. Furthermore, chart review data helped to further illuminate reasons clinicians order cardiac stress testing for patients with cerebrovascular disease. Limitations of our study are worth noting. First, given that this is an observational study rather than a randomized controlled trial, we can only comment on associations rather than causation. Second, since few patients died in our sample who had both a FCRS $\geq 20 \%$ and cardiac screening, we were unable to adjust for other important predictors of mortality and therefore were unable to assess the association between cardiac screening and 1-year allcause mortality among high-risk patients with cerebrovascular disease. As such, we were only able to examine a possible association between receiving $\mathrm{CHD}$ screening and mortality among all patients, rather than the subset of patients for which the consensus opinion was intended.
Future work should examine whether the association between receipt of cardiac stress testing for asymptomatic CHD and mortality in an exclusively high-risk cerebrovascular disease population for several treatment implications related to vascular risk factor management. For example, recent cerebrovascular prevention guidelines recommend initiation of hydrochlorothiazide or angiotensin-converting enzyme inhibitor rather than $\beta$-blocker. ${ }^{1} \beta$-blockers may less effectively prevent ischemic stroke in comparison to other agents, whereas they are the cornerstone of CHD treatment. ${ }^{11}$ Current CHD guidelines do not recommend the use of the combination aspirin/extended release dipyridamole, ${ }^{10}$ whereas there is Class I/Level of Evidence B for its use in stroke prevention. ${ }^{1}$ Third, we examined the relationship between all-cause mortality and receipt of stress testing rather than more cardiac-specific outcomes (e.g., coronary revascularization). Fourth, we cannot identify stroke subtype. Cardiac stress tests are more likely to be abnormal among patients with atherosclerotic-associated strokes compared with nonatherosclerotic strokes (50\% vs $23 \%$; $p=$ 0.04). ${ }^{30}$ Patients with cerebrovascular events secondary to cardioembolic disease and those with carotid artery disease have been found to be at high risk of having occult $\mathrm{CHD}^{3}$; interestingly, etiologies leading to cardioembolic strokes and carotid artery disease were more prevalent among those who received cardiac screening. Finally, as our cohort comprises predominantly male Veterans, these results may be less generalizable to other populations.

\section{Author contributions}

J.J. Sico: study concept and design, analysis and interpretation. F. Baye: analysis and interpretation. L. Myers: study design, critical revision of the manuscript for important intellectual content. J. Concato: study design, critical revision of the manuscript for important intellectual content. J. Ferguson: acquisition of data. E.M. Cheng: critical revision of the manuscript for important intellectual content. F. Jadbabaie: study concept and design, critical revision of the manuscript for important intellectual content. $\mathrm{Z}$. Yu: analysis and interpretation. G. Arling: study concept and design, critical revision of the manuscript for important intellectual content. A.J. Zillich: critical revision of the manuscript for important intellectual content. M.J. Reeves: study concept and design, critical revision of the manuscript for important intellectual content. L.S. Williams: study concept and design, critical revision of the manuscript for important intellectual content. Dr. Bravata: study concept and design, analysis and interpretation, critical revision of the manuscript for important intellectual content.

\section{Study funding}

This study was supported by the Department of Veterans Affairs, VHA, Health Services Research and Development Service Quality Enhancement Research Initiative Service Directed Project 12-178, and Career Development Award 11-262. 


\section{Disclaimer}

The views expressed in this article are those of the authors and do not necessarily represent the views of the Department of Veterans Affairs.

\section{Disclosure}

Dr. Sico has served on medical advisory panels for Acorda Therapeutics. J.J. Sico receives research support from the Department of Veterans Affairs. F. Baye reports no disclosures. L. Myers receives research support from the Department of Veterans Affairs. J. Concato receives research support from the Department of Veterans Affairs and Yale School of Medicine. J. Ferguson reports no disclosures. E.M. Cheng has received funding for travel from the American Academy of Neurology and receives research support from NIH (NHLBI, NINDS) and National Multiple Sclerosis Society. F. Jadbabaie and Z. Yu report no disclosures. G. Arling receives research support from the Department of Health and Human Services-CMS, AHRQ, Veterans Health Administration, and Minnesota Department of Human Services. A. J. Zillich serves as Associate Editor of Journal of the American College of Clinical Pharmacy and receives research support from the Agency for Healthcare Research and Quality, Veterans Affairs Health Services Research and Development, Purdue University College of Pharmacy, and Pharmaceutical Research Manufacturer Association Foundation. M. J. Reeves serves as a consultant for US Medical Management Inc. and receives research support from PCORI and Veterans Health Administration. L.S. Williams receives research support from Genentech and Veterans Affairs Health Services Research and Development. D.M. Bravata receives research support from Veterans Affairs Health Services Research and Development. Full disclosure form information provided by the authors is available with the full text of this article at Neurology.org/cp.

Received January 1, 2018. Accepted in final form March 16, 2018.

\section{References}

1. Kernan WN, Ovbiagele B, Black HR, et al. Guidelines for the prevention of stroke in patients with stroke and transient ischemic attack: a guideline for healthcare professionals from the American Heart Association/American Stroke Association. Stroke 2014;45:2160-2236.

2. Smith SC, Benjamin EJ, Bonow RO, et al. AHA/ACCF secondary prevention and risk reduction therapy for patients with coronary and other atherosclerotic vascular disease: 2011 update: a guideline from the American Heart Association and American College of Cardiology Foundation. Circulation 2011;124:2458-2473.

3. Adams RJ, Chimowitz MI, Alpert JS, et al. Coronary risk evaluation in patients with transient ischemic attack and ischemic stroke: a scientific statement for healthcare professionals from the Stroke Council and the Council on Clinical Cardiology of the American Heart Association/American Stroke Association. Stroke 2003;34:2310-2322.

4. Wilterdink JLF, Karen L, Easton JD. Cardiac evaluation of stroke patients. Neurology 1998;51:S23-S26.

5. Ovbiagele B, Liebeskind DS, Kim D, Ali LK, Pineda S, Saver JL. Prognostic value of Framingham cardiovascular risk score in hospitalized stroke patients. J Stroke Cerebrovasc Dis 2011;20:222-226.
6. Ovbiagele B, Liebeskind DS, Kim D, Ali LK, Pineda S, Saver JL. Optimizing screening and management of asymptomatic coronary artery disease in patients with stroke and patients with transient ischemic attack. Stroke 2009;40:3407-3409.

7. Towfighi A, Markovic D, Ovbiagele B. Utility of Framingham coronary heart disease risk score for predicting cardiac risk after stroke. Stroke 2012;43:2942-2947.

8. Bravata DM, Ho SY, Meehan TP, Brass LM, Concato J. Readmission and death after hospitalization for acute ischemic stroke: 5-year follow-up in the Medicare population. Stroke 2007;38:1899-1904

9. Touzé E, Varenne O, Chatellier G, Peyrard S, Rothwell PM, Mas J-L. Risk of myocardial infarction and vascular death after transient ischemic attack and ischemic stroke: a systematic review and meta-analysis. Stroke 2005;36:2748-2755.

10. Greenland P, Alpert JS, Beller GA, et al. 2010 ACCF/AHA guideline for assessment of cardiovascular risk in asymptomatic adults: a report of the American College of Cardiology Foundation/American Heart Association Task Force on Practice Guidelines developed in collaboration with the American Society of Echocardiography, American Society of Nuclear Cardiology, Society of Atherosclerosis Imaging and Prevention, Society for Cardiovascular Angiography and Interventions, Society of Cardiovascular Computed Tomography, and Society for Cardiovascular Magnetic Resonance. J Am Coll Cardiol 2010;56:e50-e103.

11. Wiysonge CS, Bradley H, Mayosi BM, et al. Beta-blockers for hypertension. Cochrane Database Syst Rev 2007;Cd002003.

12. Berman DS, Hachamovitch $\mathrm{R}$, Kiat $\mathrm{H}$, et al. Incremental value of prognostic testing in patients with known or suspected ischemic heart disease: a basis for optimal utilization of exercise technetium-99m sestamibi myocardial perfusion single-photon emission computed tomography. J Am Coll Cardiol 1995;26:639-647.

13. Hachamovitch R, Berman DS, Kiat H, et al. Exercise myocardial perfusion SPECT in patients without known coronary artery disease: incremental prognostic value and use in risk stratification. Circulation 1996;93:905-914.

14. Ekundayo OJ, Vassar SD, Williams LS, Bravata DM, Cheng EM. Using administrative databases to calculate Framingham scores within a large health care organization. Stroke 2011;42:1982-1987.

15. Goff DC, Lloyd-Jones DM, Bennett G, et al. 2013 ACC/AHA guideline on the assessment of cardiovascular risk: a report of the American College of Cardiology/ American Heart Association Task Force on Practice Guidelines. J Am Coll Cardiol 2014;63:2935-2959.

16. Sohn MW, Arnold N, Maynard C, Hynes DM. Accuracy and completeness of mortality data in the department of Veterans Affairs. Popul Health Metrics 2006;4:2.

17. Concato J, Peduzzi P, Holford TR, Feinstein AR. Importance of events per in dependent variable in proportional hazards analysis: I: background, goals, and general strategy. J Clin Epidemiol 1995;48:1495-1501.

18. Peduzzi P, Concato J, Feinstein AR, Holford TR. Importance of events per independent variable in proportional hazards regression analysis: II: accuracy and precision of regression estimates. J Clin Epidemiol 1995;48:1503-1510.

19. Prosser J, MacGregor L, Lees KR, et al. Predictors of early cardiac morbidity and mortality after ischemic stroke. Stroke 2007;38:2295-2302.

20. Amarenco P, Lavallee PC, Labreuche J, et al. Prevalence of coronary atherosclerosis in patients with cerebral infarction. Stroke 2011;42:22-29.

21. Members C, Gibbons RJ, Balady GJ, et al. ACC/AHA 2002 guideline update for exercise testing: summary article: a report of the American College of Cardiology/ American Heart Association Task Force on Practice Guidelines (committee to update the 1997 exercise testing guidelines). Circulation 2002;106:1883-1892.

22. Members C, Klocke FJ, Baird MG, et al. ACC/AHA/ASNC guidelines for the clinical use of cardiac radionuclide imaging: executive summary: a report of the American College of Cardiology/American Heart Association Task Force on Practice Guidelines (ACC/AHA/ASNC committee to revise the 1995 guidelines for the clinical use of cardiac radionuclide imaging). Circulation 2003;108:1404-1418.

23. Lackland DT, Elkind MSV, D'Agostino R, et al. Inclusion of stroke in cardiovascular risk prediction instruments: a statement for healthcare professionals from the American Heart Association/American Stroke Association. Stroke 2012;43:1998-2027.

24. Young LH, Wackers FJ, Chyun DA, et al. Cardiac outcomes after screening for asymptomatic coronary artery disease in patients with type 2 diabetes: the DIAD study: a randomized controlled trial. JAMA 2009;301:1547-1555.

25. Bravata D, B J, Sico JJ, et al. Vascular risk factor control in the year after ischemic stroke versus myocardial infarction. Stroke 2015;46.

26. Bagai A, Eberg M, Koh M, et al. Population-based study on patterns of cardiac stress testing after percutaneous coronary intervention. Circ Cardiovasc Qual Outcomes 2017;10.

27. Whittle J, Conigliaro J, Good CB, Lofgren RP. Racial differences in the use of invasive cardiovascular procedures in the Department of Veterans Affairs medical system. New Engl J Med 1993;329:621-627.

28. Wenneker MB, Epstein AM. Racial inequalities in the use of procedures for patients with ischemic heart disease in Massachusetts. JAMA 1989;261:253-257.

29. Lucas FL, Siewers AE, DeLorenzo MA, Wennberg DE. Differences in cardiac stress testing by sex and race among Medicare beneficiaries. Am Heart J 2007;154:502-509.

30. Chimowitz MI, Poole RM, Starling MR, Schwaiger M, Gross MD. Frequency and severity of asymptomatic coronary disease in patients with different causes of stroke. Stroke 1997;28:941-945. 


\section{Neurology ${ }^{\circ}$ Clinical Practice}

\section{Receipt of cardiac screening does not influence 1-year post-cerebrovascular event mortality}

Jason J. Sico, Fitsum Baye, Laura J. Myers, et al.

Neurol Clin Pract 2018;8;192-200 Published Online before print May 23, 2018

DOI 10.1212/CPJ.0000000000000465

This information is current as of May 23, 2018

$\begin{array}{ll}\begin{array}{l}\text { Updated Information \& } \\ \text { Services }\end{array} & \begin{array}{l}\text { including high resolution figures, can be found at: } \\ \text { http://cp.neurology.org/content/8/3/192.full.html }\end{array} \\ \text { References } & \text { This article cites } 27 \text { articles, } 18 \text { of which you can access for free at: } \\ \text { http://cp.neurology.org/content/8/3/192.full.html\#\#ref-list-1 } & \text { This article, along with others on similar topics, appears in the } \\ \text { following collection(s): } & \text { All Cerebrovascular disease/Stroke } \\ \text { http://cp.neurology.org//cgi/collection/all_cerebrovascular_disease_stro } & \text { ke } \\ & \text { Information about reproducing this article in parts (figures,tables) or in } \\ \text { its entirety can be found online at: } & \text { http://cp.neurology.org/misc/about.xhtml\#permissions } \\ \text { Permissions \& Licensing } & \begin{array}{l}\text { Information about ordering reprints can be found online: } \\ \text { http://cp.neurology.org/misc/addir.xhtml\#reprintsus }\end{array} \\ \text { Reprints } & \end{array}$

Neurol Clin Pract is an official journal of the American Academy of Neurology. Published continuously since 2011, it is now a bimonthly with 6 issues per year. Copyright copyright @ 2018 The Author(s).

Published by Wolters Kluwer Health, Inc. on behalf of the American Academy of Neurology.. All rights reserved. Print ISSN: 2163-0402. Online ISSN: 2163-0933.

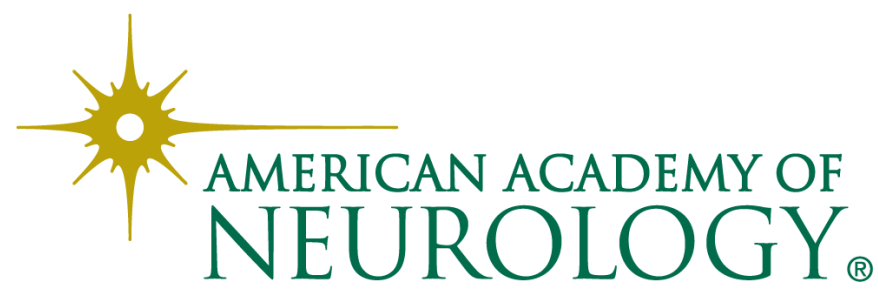

